\title{
RECONFIGURAÇÃO DO MUNDO DO TRABALHO: O GÊNERO COMO CATEGORIA ESSENCIAL AO DEBATE
}

\author{
Reconfiguration of the world of work: gender as an essencial category of \\ debate
}

João Matheus Soares Miranda'

\begin{abstract}
Resumo
0 presente artigo busca apresentar o gênero como categoria essencial aos debates ensejados pelas reconfigurações do mundo do trabalho. Os esforços depositados na temática surgem a partir de uma experiência pessoal onde o debate sobre o gênero em um projeto de Doutorado suscitou a relevância de imprescindíveis e inadiáveis esforços de compreensão dos fenômenos em questão. Levando em consideração as condições sócio históricas marcadas pela desigualdade e hierarquização entre homens e mulheres no campo social, o inevitável enfrentamento também ganha destaque nas relações laborais marcadas igualmente por processos contínuos de dominação e distintas formas de opressão. Aspectos relevantes dos desdobramentos de uma cultura laboral que raramente dedica atenção suficiente à centralidade do gênero também são apresentados nas linhas a seguir, bem como as implicações das desigualdades e assimetrias identificadas na sistematização do capitalismo contemporâneo.
\end{abstract}

Palavras-chave: Gênero; Mulheres; Trabalho; Desigualdade.

\begin{abstract}
The present article seeks to present gender as an essential category for the debates brought about by the reconfigurations of the world of work. The efforts deposited in the theme come from a personal experience where the debate about gender in a $\mathrm{PhD}$ project has raised the relevance of indispensable and unavoidable efforts to understand the phenomena in question. Taking into account the sociohistorical conditions marked by the inequality and hierarchy between men and women in the social field, the inevitable confrontation also gains prominence in labor relations marked by continuous processes of domination and different forms of oppression. Relevant aspects of the unfolding of a labor culture that rarely pays enough attention to the centrality of gender are also presented in the following lines, as well as the implications of the inequalities and asymmetries identified in the systematization of contemporary capitalism.
\end{abstract}

Keywords: Gender; Women; Work; Inequalities.

\section{Introdução}

Embora as lições dos manuais acadêmicos e a tradição linguística da comunicação de caráter científico costumeiramente não indiquem a redação

\footnotetext{
${ }_{1}^{1}$ Doutorando do Programa de Pós-Graduação em Sociologia da Universidade Federal de Pelotas (UFPel). E-mail: joaomatheusmiranda@hotmail.com
} 
A reconfiguração do mundo do trabalho: o gênero como categoria essencial ao debate | João Matheus Soares Miranda

de textos e artigos no tempo verbal da primeira pessoa do singular, lanço mão desse artificio de escrita que, não apenas favorece o entendimento da proposta por hora apresentada, mas igualmente contribui ao desafio de justificar a escolha da temática em debate. Cumpre salientar que, ao término da explanação necessária à introdução do artigo (a partir de uma lógica argumentativa que favorece a fluidez textual), voltaremos ao tradicional uso da terceira pessoa do singular, com a devida sinalização indicativa sobre a virada da linguagem para a forma academicamente mais usual.

Diante da breve explicação que assegura a questão de ordem e entendimento sobre as linhas que seguem, vale comentar sobre as razões que deram vazão ao esforço de empreender um debate sobre a categoria gênero nas relações de trabalho. Em um modelo econômico e social marcado pela reconfiguração das lógicas que dimensionam a cultura do labor, desde as formas de contratação ao caráter de transmutação da subjetivação do trabalhador em relação ao modo de encarar os sentidos do trabalho pósfordista, o gênero se dimensiona como uma variável fundamental ao esforço de compreender o capitalismo dos nossos tempos. Essa é a proposta que alicerça o presente trabalho.

No início do ano de 2019, diante de um processo seletivo do Doutorado no Programa de Pós Graduação em Sociologia, na Universidade Federal de Pelotas - RS, submeti à banca avaliadora um projeto com o seguinte título: "A ordem celetista em risco ou maquiagem e perfumaria? "Parceiras, Representantes e Consultoras: a reconfiguração das subjetividades de trabalhadoras vinculadas por regimes alternativos a empresas do ramo cosmético no Rio Grande do Sul”. O objetivo principal do projeto buscava compreender como as então nomeadas parceiras, representantes e consultoras de empresas do setor cosmético desempenhavam seus papéis na organização social do trabalho a partir da reconfiguração de suas subjetividades diante da lógica pós-celetista.

Durante a produção do projeto me certifiquei de que a proposta de pesquisa estivesse bem estruturada sob os moldes que tradicionalmente são levados em consideração no momento de avaliação. Interessava apresentar 
A reconfiguração do mundo do trabalho: o gênero como categoria essencial ao debate | João Matheus Soares Miranda

um projeto que efetivamente se transformasse em uma tese de relevante valor acadêmico, de fôlego e vigor. $\mathrm{O}$ recorte temático adequadamente ajustado a partir do problema de pesquisa, bem como a justificativa arrazoada em um padrão que ensejaria fluidez aos objetivos e hipóteses me faziam crer que, minimamente, uma proposta estruturada se desenhava de forma satisfatória.

Busquei no referencial teórico explicar como a noção do lastro sóciometabólico do capital utilizada por Alves (2008), amparada na metáfora da vida metabólica de István Mészáros, poderia contribuir ao intento de compreender as relações de trabalho na organização do capitalismo pela constante relação entre corpo/mente e os esforços do capital em interferir nas subjetividades dos trabalhadores inseridos no sistema pós-fordista. Ainda, me debrucei vigorosamente sobre os estudos de sociologia do trabalho que pudessem contribuir ao desafio de respaldar a futura tese. Quero dizer, portanto, que me dediquei ao máximo para que o projeto fosse avaliado positivamente e o objetivo de ingressar no Doutorado pela seleção se tornasse exitoso.

Chegado o dia da arguição do projeto de pesquisa, etapa de seleção frente à banca, tive a oportunidade de apresentar com maior detalhamento a minha ideia de tese. O andamento da defesa transcorria dentro da normalidade até que, em determinado momento, um das Professoras integrantes do corpo docente teceu um comentário certeiro sobre uma fragilidade que até então não havia percebido: "o teu projeto busca trabalhar com uma atividade desempenhada por mulheres, mas em nenhum momento o gênero é apresentado ou circunda a tua discussão...falta isso!".

A clareza da crítica foi direta, indicando que, por vezes, o óbvio passa ao largo dos nossos sentidos. Como pude não perceber essa constatação quase lógica? Injustificável, por exemplo, não trazer as produções de Helena Hirata ao debate, autora imprescindivel no entendimento das questões de gênero no mundo do trabalho e cujo alguns artigos e capítulos de livros já 
A reconfiguração do mundo do trabalho: o gênero como categoria essencial ao debate | João Matheus Soares Miranda

haviam passado pelas minhas mãos. Constatei que além da correção de rumo sobre o projeto de tese, restava chamar ao debate das relações de trabalho o gênero, em uma inadiável necessidade de compreender os processos sociais que são específicos à dimensão do labor feminino.

$\mathrm{O}$ intuito do presente artigo, por uma questão lógica, nada tem a ver com uma apropriação da pauta das mulheres, menos ainda a pretensão de ocupar um espaço que é por direito delas, mas contribuir a partir da sociologia com o debate sobre a essencialidade do gênero ao movimento de compreensão do capitalismo e as relações de trabalho advindas do modelo. Nesse sentido, apresento a divisão do artigo em três outras partes além da introdução já desenvolvida: um debate sobre a centralidade do gênero no mundo laboral e a importância das contribuições teóricas e temáticas sobre as relações sociais advindas dos processos históricos; gênero e trabalho: implicações das desigualdades e os reflexos das sistemáticas hierarquizações e opressões sofridas pelas mulheres na lógica social e, por consequência, no mundo do trabalho; considerações finais buscando enlaçar os capítulos em uma ordem que consiga viabilizar o debate sobre um tema que tende a ganhar novos contornos tendo em vista a dinâmica das relações de trabalho na contemporaneidade.

\section{A centralidade do gênero?}

O mundo do trabalho é um campo de estudos historicamente conflituoso, não apenas pela essência de disputa que fundamenta a razão de existir e funcionar do sistema capitalista, mas pelas próprias contradições que envolvem as relações sociais de suas operações. Queremos ${ }^{2}$ dizer que as amplas mudanças ocorridas nas últimas décadas, especialmente pela assimilação de um período informacional e tecnológico (CASTELLS, 1999), calcado na noção de globalização, deram vazão a movimentos de transformações e ressignificações no mundo do trabalho. Diferentes autores e autoras se debruçaram sobre o tema, trazendo à discussão perspectivas distintas, olhares sociológicos relevantes, porém, com limitações

\footnotetext{
2 Utilizamos a partir de então o tempo verbal de terceira pessoa para melhor adequação e fluidez
} textual. 
A reconfiguração do mundo do trabalho: o gênero como categoria essencial ao debate | João Matheus Soares Miranda

compreensiveis frente aos interesses e possibilidades de cada pesquisa ou contribuição. A década de 1980, especialmente, se configura como um marco temporal de extrema fertilidade dos estudos de gênero e feminismo, ainda que sob perspectivas parcialmente diferentes, com teóricas buscando "produzir deslocamentos nos paradigmas disciplinares no marco dos quais trabalhavam" (PISCITELLI, 2008, p. 264). É justamente no interesse de ampliarmos o debate que recorremos aos estudos de gênero para avançarmos na empreitada sociológica de continuar desbravando a categoria no multifacetado mundo do trabalho.

O debate que se apresenta diz respeito ao gênero como categoria fundamental à compreensão das relações de labor no capitalismo, ou, partindo da lógica crítica do que se classificou "capitalismo patriarcal", o enfrentamento da opressão que articula modelo econômico e dominação pelo gênero (KERGOAT, 1978). Contribuições de estudos interseccionais fortalecem a argumentação de que as relações sociais estão fortemente marcadas por fatores de desigualdades e hierarquizações. Nessa(s) linha(s) teórica(s), as variáveis gênero, raça e classe se apresentam como objetos relacionais dos estudos e análises que tenham o intuito de efetivamente desnudar os sistemas de opressão existentes. No entanto, como veremos adiante, essa posição teórica encontra apontamentos importantes de correntes identificadas por uma linha essencialmente critica da sociologia do trabalho.

Embora não seja a centralidade do presente trabalho esmiuçar a lógica da tríade interseccional, é preciso salientar que essa proposta de explicação e entendimento social se arregimenta por frentes teóricas distintas. Contribuições de Miguel e Biroli (2015), por exemplo, apresentam um importante panorama sobre as desigualdades nas sociedades contemporâneas partindo da articulação interseccional. Para tanto, discutem as teorias feministas marxistas ou socialistas, o feminismo negro e os estudos das interseccionalidades, apontando a necessidade de 
A reconfiguração do mundo do trabalho: o gênero como categoria essencial ao debate | João Matheus Soares Miranda

abordagens que contemplem o caráter associativo das frentes temáticas.

\begin{abstract}
Uma análise focada nas relações de classe pode deixar de fora o modo como as relações de gênero e o racismo configuram a dominação no capitalismo, posicionando as mulheres e a população não-branca em hierarquias que não estão contidas nas de classe, nem existem de forma independente e paralela a elas. Reduz, com isso, sua capacidade de explicar as formas correntes de dominação e os padrões de desigualdade. Do mesmo modo, uma análise das relações de gênero que não problematize o modo como as desigualdades de classe e de raça conformam o gênero, posicionando diferentemente as mulheres nas relações de poder e estabelecendo hierarquias entre elas, pode colaborar para suspender a validade de experiências e interesses de muitas mulheres. Seu potencial analítico assim como seu potencial transformador são, portanto, reduzidos (MIGUEL; BIROLI, 2015, p. 29-30).
\end{abstract}

Como salientamos anteriormente, os debates sobre a tríade interseccional não se instauram como objetos de aprofundamento da presente proposta. Devemos, no entanto, chamar atenção ao fato de que há décadas autoras travam significativas discussões no intento de avançar sobre as questões das desigualdades, onde a constatação da opressão de gênero parece ser o grande ponto de consenso entre as correntes que se lançam ao debate. Inclusive, vale salientar, que a própria noção de interseccionalidade é debatida e, sob certa medida, criticada. Kergoat (2010), por exemplo, problematiza o caráter interseccional que não aprofunda a crítica às relações sociais e a dominação existente que se origina do caráter histórico e material da sociabilidade. Ainda, podemos citar Hirata (2014, p. 66), fazendo referência ao que chamou de "interseccionalidade de geometria variável", enquadrando no espectro outras categorizações importantes como "sexualidade, idade e religião".

É, portanto, debate que traz à baila propostas que mobilizam epistemologicamente lentes teóricas que, vez ou outra, por explicações que seguidamente estão relacionadas às experiências e trajetórias de quem escreve, se distinguem pelo destaque que atribuem à determinada categoria. Ainda que distanciamentos e aproximações ocorram em menor ou maior grau, é razoável o entendimento de que "as relações sociais de gênero, de raça e de classe são interdependentes e indissociáveis" (HIRATA, 2018, p.17).

$O$ que se coloca em debate é como o gênero e a importância da temática sobre as trabalhadoras mulheres são atravessados pela organização social a partir do capitalismo e as suas formas de dominação. Ainda que distintas categorias de análise e correntes teóricas disputem espaço no 
A reconfiguração do mundo do trabalho: o gênero como categoria essencial ao debate | João Matheus Soares Miranda

desafio científico e acadêmico de ofertar as mais completas e expressivas contribuições aos estudos de gênero, é no mundo do trabalho, na sociologia que se debruça sobre as sociabilidades laborais, que conseguiremos estreitar a compreensão devida entre o que se chama de mercado de trabalho, o labor para sustento das necessidades materiais triviais no capitalismo, e as implicações de "ser mulher" em um modelo que sistematiza hierarquicamente os gêneros, ocasionando reflexos de ordem simbólica e material. É nesse sentido que a centralidade do gênero é concebida em nossa proposta de contribuição e entendimento: como um elemento de análise imprescindivel ao mundo do trabalho de reconfigurações cada vez mais dinâmicas, seja da expressão sistêmica que se sustenta no capitalismo ou nas condições relacionadas e originadas pelos processos socio-históricos de hierarquizações e desigualdades.

\section{Gênero e trabalho: implicações das desigualdades}

Buscamos demonstrar que os estudos sobre o gênero estão configurados por uma lógica ampla e diversa, articulada por outros elementos importantes ao desafio teórico e epistemológico que a realidade apresenta aos que se debruçam sobre o tema. A condição do gênero na representação do mundo do trabalho e as desigualdades que perpassam as relações sociais estabelecidas historicamente que, não por acaso, se caracterizam por um modelo de privilégio e opressão, permanecem como debates atuais (e inadiáveis) na contemporaneidade. Ademais, constatamos a vastidão de contribuições de diferentes autoras que, cada qual partindo de categorias, em tese, distintas, se caracterizam por afirmar na condição do gênero um elemento de análise crucial para o desenvolvimento dos seus estudos. Embora as temáticas por vezes partam de pressupostos distintos, nos importa salientar como estreitar as abordagens sociológicas pelo debate do gênero pode se constituir como uma alternativa eficaz ao desafio de desnudar as relações sociais contemporâneas.

As pesquisas e abordagens comparativas entre países (HIRATA; 
A reconfiguração do mundo do trabalho: o gênero como categoria essencial ao debate | João Matheus Soares Miranda

GUIMARÃES; SUGITA, 2009), as dimensões oriundas pelos fluxos migratórios (PISCITELLI, 2008), a constatação da precarização do trabalho e os regimes de flexibilidade (HIRATA, 2005), a organização dos dados e análise das assimetrias e desigualdades (GUIMARÃES, 2004), o gênero como elemento articulador essencial das relações sociais (BRUSCHINI, 1994; 2007). Todos os exemplos referenciados se apresentam como esforços, embora marcados por características de cada proposta, de alçar o gênero como força motriz da compreensão teórica e epistemológica. Esse é o fator que desencadeia a lógica necessária e que se inscreve como argumento inicial da proposta: conseguir estabelecer a relação que se origina entre as condições impostas pelo mundo do trabalho no seu processo de reconfiguração e sua imbricação com o gênero.

Embora nosso objetivo seja avançar sobre a importância do debate sobre gênero a partir de um enquadramento pelo mundo do trabalho, o questionamento se apresenta quase como um suspiro da contradição: é possivel compreender o estabelecimento das relações sociais oriundas da dinâmica do capitalismo sob o enfoque do gênero sem discutirmos os processos que sistematizam a lógica da dominação? Reside justamente nesse ponto a centralidade da desigualdade entre os gêneros. A ideia, portanto, que o mundo do trabalho não pode ser observado apartado de uma teorização que confira às opressões de gênero papel de destaque, se consolida e ganha espaço, especialmente pela contribuição incansável das autoras anteriormente citadas.

Existe um caminho teórico que apresenta importante crítica, não apenas à desigualdade de gênero e seus efeitos, mas igualmente concentra esforços no embate com o sistema legitimador e causador das relações de assimetria, incidindo definitivamente no mundo do trabalho. É nesse sentido que HIRATA e KERGOAT (2007, p. 599-600) analisam a divisão sexual do trabalho. Vejamos:

[...] desde o nascimento do conceito há cerca de trinta anos, se observa uma tensão entre, de um lado, análises que pensam mais em termos de constatação de desigualdades entre homens e mulheres, e de acúmulo, de soma dessas desigualdades (cf. a noção atual de conciliação de tarefas), e, de outro lado, análises que procuram remontar à nascente dessas desigualdades e, portanto, compreender a natureza do sistema que dá origem a elas. Subentende que é nesse quadro de reflexão que nos 
A reconfiguração do mundo do trabalho: o gênero como categoria essencial ao debate | João Matheus Soares Miranda

inscrevemos. [...] sempre que se tenta fazer um balanço da divisão sexual do trabalho em nossas sociedades, se chega à mesma constatação em forma de paradoxo: nessa matéria, tudo muda, mas nada muda.

Resta evidente que as autoras não se conformam exclusivamente com mero movimento de constatação das desigualdades socialmente construídas. Ademais, chamam atenção ao fato de que a ordem social que oportuniza o caráter desequilibrado das relações imprescinde de uma reflexão com base em um enfrentamento que rompa a historicidade até então duradoura. As forças de dominação e a imposição pelo poder se articulam como elementos legitimadores de um enquadramento que tende à lógica contínua da sua estruturação.

Mas afinal de contas, como se estabelece a divisão social do trabalho quando elencamos o gênero como centralidade no debate? Tomamos como ponto de partida as definições estabelecidas que expressam dois sentidos que dimensionam e dão o tom das relações consequentes da divisão a partir do gênero. Conforme Hirata e Kergoat (2007, p. 599-600), dois princípios sustentam a divisão social do trabalho, quais sejam: I) princípio da separação, que diz respeito aos tipos de trabalhos exercidos; II) princípio hierárquico, que, como indica a nomenclatura, suscita a ideia da assimetria entre os gêneros no mundo do trabalho. As autoras afirmam o caráter histórico dos princípios, bem como o caráter ideológico que se funda no naturalismo biológico para abarcar uma forma de legitimação de práticas díspares na divisão sexual do trabalho (HIRATA e KERGOAT, 2007, p. 599600). Reside nesse contexto, que cristaliza a diferença biológica em ordem de manutenção sistemática de privilégio do gênero, o campo de disputa que atinge com maior força as mulheres: o mundo do trabalho.

Em Adeus ao trabalho? ensaio sobre as metamorfoses e a centralidade do mundo do trabalho, Antunes (2015, p. 140), em capítulo que aborda de forma sintética e precisa a perenidade e superfluidade do trabalho do presente (com importantes reflexões sobre as teses futuras), indica que para nos aprofundarmos sobre o caráter polissêmico e multifacetado do 
A reconfiguração do mundo do trabalho: o gênero como categoria essencial ao debate | João Matheus Soares Miranda

capitalismo, é essencial compreendermos o expressivo "processo de feminização do trabalho que atinge mais de $40 \%$ ou $50 \%$ da força de trabalho em diversos países, e que tem sido absorvido pelo capital, preferencialmente no universo do trabalho part-time, precarizado e desregulamentado". A informação levantada por Antunes apresenta não apenas um dado representativo, mas um indicativo de valoração de uma lógica social que deposita no trabalho feminino, sob forma da precariedade, é verdade, um papel na organização do universo laboral do capitalismo.

Percebam que podemos colocar sob enfoque da nossa apreciação dois principais pontos do excerto referenciado, a saber: a feminização do trabalho e os processos de desregulamentação e precarização do trabalho a serviço do capital. São fatores que se inscrevem concomitantes às relações laborais e que carregam consigo toda a herança da desigualdade existente, pelo gênero e classe. Ou por acaso a divisão social do trabalho não se arregimenta pelas já debatidas (e nem sempre enfrentadas) condições de exploração, com o agravante da hierarquização entre os gêneros?

[...] a maioria das atividades de concepção ou aquelas baseadas em capital intensivo são realizadas pelo trabalho masculino, enquanto aquelas dotadas de menor qualificação e frequentemente fundadas em trabalho intensivo destinam-se sobretudo às mulheres trabalhadoras [...], ainda mais, através da duplicidade do ato laborativo, a mulher trabalhadora é duplamente explorada pelo capital, tanto no espaço produtivo como no reprodutivo. Além de atuar crescentemente no espaço público, fabril e de serviços, ela realiza centralmente as tarefas próprias do trabalho doméstico, garantindo a esfera da reprodução societal, esfera do trabalho não diretamente mercantil, mas indispensável para a reprodução do sistema de metabolismo social do capital (ANTUNES, 2015, p. 140 - 141).

Quando salientamos que o gênero deve ser percebido como um elemento de centralidade da compreensão do mundo do trabalho reconfigurado, partimos do pressuposto que a lógica capitalista já condiciona relações de precarização do labor na chamada escala global. Significa, portanto, que a divisão sexual do trabalho ultrapassa a barreira da mera desigualdade, incidindo, na verdade, sobre um sistema que articula diferenciação e hierarquização não somente de atividades, mas sobre a figura do gênero nas relações sociais (HIRATA e KERGOAT, 2007, p. 596).

Buscando aproximar os elementos que sustentam a condição do gênero nas esferas sociais, Bruschini (1994) contribuiu trazendo ao debate 
A reconfiguração do mundo do trabalho: o gênero como categoria essencial ao debate | João Matheus Soares Miranda

reflexões sobre a tríade "família, casa e trabalho", os espaços de assimilação e legitimação de uma ordem marcada pela desigualdade, além de chamar atenção ao fato de que:

\begin{abstract}
A primeira geração de estudos sobre trabalho feminino, no Brasil, focalizou exclusivamente a ótica da produção, sem levar em conta o fato de que o lugar que a mulher ocupa na sociedade também está determinado por seu papel na família. O debate teórico e as pesquisas sobre o trabalho feminino tomaram um novo rumo quando passaram a focalizar a articulação entre o espaço produtivo e a família, ou espaço reprodutivo. Pois, para as mulheres, a vivência do trabalho implica sempre a combinação dessas duas esferas, seja pela articulação, seja pela superposição, tanto no meio urbano quanto no rural (BRUSCHINI, 2007, p. 542).
\end{abstract}

O ponto levantado evidencia características comuns ao trabalho feminino que despontam com maior relevância quando analisadas sob a luz das relações estabelecidas no Brasil. Traço da nossa sociedade, a diferenciação que atinge as mulheres no mercado de trabalho encontra lógica ainda mais assimétrica quando outras variáveis se inscrevem potencialmente à análise, concomitantemente ao gênero. Bruschini (1994, p. 35) conclui que embora os conceitos "família, casa e gênero" sejam marcados pela fluidez, ou seja, se imbricam na lógica de suas funcionalidades enquanto categorias materiais na vida dos indivíduos, suas aproximações encontram variações e forças de relação que variavelmente se configuram conforme as estruturas socioeconômicas dos lares. Significa que o trabalho desempenhado pelas mulheres pode encontrar lógicas diversas conforme a condição familiar em termos de rendimento-remuneração e a posição ocupada na disposição familiar.

A afirmação da distinção entre o trabalho masculino e feminino se assegura também pelo caráter social que a divisão do trabalho produziu. Os afazeres domésticos, historicamente resguardados sob a responsabilidade das mulheres nos lares, ainda condicionam a relação entre gênero e trabalho. Bruschini (2007, p. 542) salienta que "as mulheres permanecem como as principais responsáveis pelas atividades domésticas e cuidados com os filhos e demais familiares, o que representa uma sobrecarga para aquelas que também realizam atividades econômicas". Ainda, explica que embora a 
A reconfiguração do mundo do trabalho: o gênero como categoria essencial ao debate | João Matheus Soares Miranda

categoria "afazeres domésticos" não seja contemplada como "formas de trabalho" pelos dados oficiais ${ }^{3}$, os reflexos dessas atividades estão presentes diretamente na relação entre gênero e trabalho-emprego no Brasil. Podemos argumentar que as atividades desempenhadas por inúmeras mulheres nos lares produzem efeitos diretos no mundo do trabalho:

[...] arrumar ou limpar toda ou parte da moradia; cozinhar ou preparar alimentos, passar roupa, lavar roupa ou louça, utilizando, ou não, aparelhos eletrodomésticos para executar tarefas para si ou para outro(s) morador(es); orientar ou dirigir trabalhadores domésticos na execução das tarefas domésticas; cuidar de filhos ou menores moradores; limpar o quintal ou terreno que circunda a residência (BRUSCHINI, 2007, p. 544).

$\mathrm{Na}$ tentativa de situar as mulheres na lógica do capitalismo nacional, levando em consideração o perfil das trabalhadoras no mercado, algumas considerações merecem destaque, especialmente por conseguirem estabelecer um movimento de compreensão sobre o "destaque" da mulher brasileira em suas atividades laborais, pelos fatores de inserção, permanência e, infelizmente, precariedade.

O desafio da inserção no mercado de trabalho se apresentou historicamente às mulheres brasileiras na porção da população economicamente ativa. O desemprego feminino, costumeiramente relacionada à "falta" de trabalho, em comparação à realidade masculina, sempre apresentou taxas mais elevadas, "entretanto, a partir dos anos 90 a desocupação tornou-se muito mais forte entre as mulheres, cuja taxa de desemprego se dissociaram do padrão até então compartilhado (embora com magnitudes diferentes entre homens e mulheres") (GUIMARÃES, 2004, p. 316).

A contradição expressa na dinâmica da inserção das trabalhadoras no mercado de trabalho apresenta variações que dizem respeito ao perfil das mulheres e as atividades desempenhadas. Podemos, por exemplo, suscitar os estudos comparados de Hirata (2009) que tratam do que a autora chama de "consequências paradoxais da globalização". O movimento que indica aumento da inserção feminina no mercado de trabalho também oferta

\footnotetext{
3 Bruschini (2007) trabalha com os dados do PNAD.
} 
A reconfiguração do mundo do trabalho: o gênero como categoria essencial ao debate | João Matheus Soares Miranda

indícios para se pensar sobre a qualidade dos trabalhos e empregos desempenhados pelas mulheres. Embora a globalização sob certa medida se apresente como vetor de "desenvolvimento" na criação de oportunidades, o paradoxo se constituiu na qualidade dos trabalhos e empregos gerados pela economia de mercado. A realidade apresentada pelos estudos comparados indica que a participação feminina nos postos ocupados é marcada por "ocupações mal remuneradas, desvalorizadas socialmente e com possibilidades quase nulas de promoção e de carreira, além de amparadas por direitos sociais frequentemente limitados ou inexistentes, isso vale para a Ásia tanto quanto para Europa e América Latina" (HIRATA, 2009, p. 149).

As discussões que se destacam quanto à reconfiguração dos trabalhos e empregos, constatações de precariedades e informalidades (DRUCK, 2002), autoempreendedorismo (ROSENFIELD, 2015), abordagens sobre a polissemia do "novo espírito do capitalismo" (BOLTANSKI; CHIAPELLO, 2009) e o caráter multifacetado do trabalho pós-fordista (ANTUNES, 2013), por exemplo, não podem escapar aos elementos gênero e trabalho, essenciais à equação que desnuda as relações laborais no que se denominou globalização.

O ponto de tensão reside justamente nas diferenças fundamentais que acompanham as trajetórias dos diferentes perfis de mulheres que se inscrevem como potenciais ocupantes dos cargos e postos de trabalho. Bruschini chama atenção às conquistas atribuídas às mulheres no que diz respeito ao incremento da escolarização e formação universitária, viabilizando um novo patamar e alternativas de trabalho, indicando um momento de transformação da força de trabalho feminina. "As trabalhadoras, que, até o final dos anos 70 , em sua maioria, eram jovens, solteiras e sem filhos, passaram a ser mais velhas, casadas e mães" (BRUSCHINI, 2007, p. $541)$.

Devemos avançar na necessária avaliação do perfil que se estabelece entre as trabalhadoras no mundo do trabalho globalizado. Para tanto, 
A reconfiguração do mundo do trabalho: o gênero como categoria essencial ao debate | João Matheus Soares Miranda

lançamos mão, mais uma vez, das constatações que se sustentam pela noção diferencial entre Norte e Sul global e o lugar do trabalho feminino nessa lógica de distanciamentos e aproximações. Hirata (2009, p.149) indica ser possivel falarmos em aproximações no que diz respeito ao debate sobre a qualidade dos trabalhos-empregos e contratos (a falta deles por vezes) entre os hemisférios. Enquanto no Norte a flexibilização do trabalho pela dimensão do tempo parcial marcou os modelos contratuais das trabalhadoras, no Sul, por sua vez, a autora indica a ausência da proteção social como importante fator de análise sobre o caráter qualitativos dos postos e funções designados às mulheres. O resultado desse paradoxo é a simbologia da desigualdade que afeta, ainda que de formas distintas, as porções de mulheres "pobres ("working poors") e famílias monoparentais, termo neutro que esconde o fato de que se trata majoritariamente de mães solteiras", com presença nos dois polos (HIRATA, 2009, p. 149).

$\mathrm{Na}$ esteira de análise a partir da bipolarização global, as condições dos empregos femininos também são ponto de congruência entre Norte e Sul no que diz respeito às distinções endossadas por fatores educacionais. Significa, portanto, que é possivel observarmos aumento da participação de mulheres, qualificadas pela escolarização e formação, em funções e atividades de prestígio social que até então eram predominantemente masculinas. Por outro lado, os setores que tradicionalmente abarcam contingente expressivo de mulheres, trabalhos ditos femininos ${ }^{4}$, continuam expressando a "exacerbação das desigualdades sociais e dos antagonismos", em uma lógica que acentua os ditames da divisão social do trabalho pautados pelas questões do gênero; (HIRATA, 2009, p. 149). A globalização atinge em gradações nem sempre similares as relações de trabalho sob a ordem da qualidade dos postos ofertados, mas é possivel arriscarmos dizer que o gênero inevitavelmente será parâmetro para o real entendimento do

\footnotetext{
4 Helena Hirata (2009, p. 149) classifica algumas modalidades de trabalhos tradicionalmente femininos: "empregadas do setor público, da saúde, da educação, do setor da prestação de serviços, técnicas de enfermagem, enfermeiras, professoras de escolas maternais, profissionais do "care" que se ocupam de idosos, dos doentes, das crianças, e do trabalho doméstico, como empregadas e diaristas".
} 
A reconfiguração do mundo do trabalho: o gênero como categoria essencial ao debate | João Matheus Soares Miranda

nível de precarização e flexibilização das vinculações e atividades, pelo menos enquanto não houver uma readequação minimamente solidária aos valores de igualdade na divisão social do trabalho, no Norte ou Sul global.

$\mathrm{Na}$ medida que avançamos sobre os percalços que envolvem os processos de inserção das trabalhadoras nos postos de trabalho e emprego, levando em consideração a dimensão que o gênero apresenta ao debate, novos desdobramentos surgem, escorados no paradoxo da globalização. Hirata (2005, p. 114), contribui lançando criticamente o seguinte questionamento ao debate: "a globalização está enfraquecendo ou fortalecendo o antagonismo social de classes, gênero-"raça"/etinicidade? Enquanto as condições de emprego e salariais foram afetadas pelo processo de flexibilização, grupos políticos e atores coletivos de posição crítica aos preceitos da globalização puderam se formar diante dessa pauta comum, a busca por uma contra-hegemonia, ou seja, a manifestação evidente dos paradoxos da globalização. É nesse sentido que a própria noção de globalização e suas possibilidades de significação ganham novos contornos: pela capacidade de articular discursos que até então se dispersavam na vastidão das experiências de gênero mundo afora, nas mais variadas possibilidades de emergências dos feminismos que se apresentaram nesse século (PINTO, 2017).

A centralidade do gênero, como buscamos demonstrar até aqui, não se limita ao caráter meramente conceitual do debate sobre a representação feminina na divisão social do trabalho. Muito além disso, é a organização social historicamente constituída, ou seja, o sistema hierarquizante e de assimetrias emoldurado pela opressão sofrida pelas mulheres, que reverbera e dá o tom da lógica espelhada nas questões relativas ao labor feminino e suas peculiaridades.

O mundo do trabalho, compreendido pelas lentes teóricas que então dispomos, sinaliza como mais um campo onde o gênero se arregimenta como elemento de disputa, enfrentamentos e antagonismos. Por isso a importante 
A reconfiguração do mundo do trabalho: o gênero como categoria essencial ao debate | João Matheus Soares Miranda

mobilização em torno de ações e reivindicações que se pautam pelos movimentos das mulheres, teorias feministas ${ }^{5}$ e suas formas de organização. Se a centralidade do gênero nas relações de trabalho também opera sob a lógica da dominação, os efeitos dessa realidade de desigualdade não podem ser tomados como estáticos e determinados, "mas, sim, como um dado fundamental a ser tomando em consideração, tanto na análise do problema como na decisão de ações concretas para transformar a posição das mulheres nos espaços de poder" (PINTO, 2010, p. 22).

Ao considerarmos que a realidade da dominação não pode ser observada por uma perspectiva de determinação absoluta, ou seja, existem formas de mobilização que se orientam em vetor inverso ao processo de opressão, é importante evidenciarmos o questionamento que Hirata apresenta e, imediatamente, procura responder:

\begin{abstract}
Como superar essas desigualdades e romper com a desigual divisão sexual do trabalho existente nas sociedades contemporâneas? A minha hipótese é de que não podemos mudar a divisão sexual do trabalho profissional, sem mudar a divisão sexual do trabalho doméstico, a divisão sexual do poder e do saber na sociedade (HIRATA, 2015, p. 18).
\end{abstract}

Mas se há, conforme a autora, indicação e pistas para o caminho que possibilita a mudança necessária à estrutura atual da divisão social do trabalho, é no próprio movimento articulado de mulheres que a efetividade para a trilha do percurso se sustenta. Embora, por exemplo, não seja possivel falarmos em um movimento feminista de enfrentamento às desigualdades, mas de feminismos, no plural, existe nessa articulação discursiva uma cadeia de equivalências que se levantam contra uma lógica hegemônica de hierarquização e dominação pelo gênero (PINTO, 2010).

O contexto que apresenta o gênero como elemento essencial ao entendimento das relações de trabalhos contemporâneas perpassa também por um cenário que se dimensiona pela classe. Ora, se constatamos que as condições de inserção e permanência de mulheres nos postos de mercado de

\footnotetext{
5 Chamamos atenção ao artigo "É possivel falar de um discurso feminista no século XXI?" onde Céli Regina Jardim Pinto (2017) apresenta uma abordagem teórico-metodológica dos feminismos a partir de Laclau e Mouffe. Nesse sentido, a autora apresenta sua análise de dados tendo como base: Coletivo Socialista Feminista (Istanbul- Turquia), Amargi (Istanbul- Turquia), Coletivo de Mulheres de Tamilnadu (india), Feministindia, Marcha das Vadias (São Paulo), Marcha das Vadias de Singapura, FEMEN e a Marcha Mundial das Mulheres.
} 
A reconfiguração do mundo do trabalho: o gênero como categoria essencial ao debate | João Matheus Soares Miranda

trabalho estão criticamente sujeitadas aos reflexos da lógica da divisão sexual do trabalho, ou seja, marcadas pela assimetria e hierarquização, não seria a classe um importante elemento ao desafio de compreendermos a centralidade do gênero nas relações de trabalho? Acenamos positivamente à pergunta. Importa dizer, no entanto, que existe um debate ainda vigoroso e contundente em torno de contribuições que dialogam (e constantemente divergem) sobre o binômio gênero e classe. Nesse sentido, as noções de interseccionalidade apresentam um aparato conceitual e teórico que se articulam e contribuem ao desafio que se apresenta, introduzindo a raça como categoria de análise ao problema, fundamentalmente pelos esforços de feministas negras (MIGUEL; BIROLI, 2015).

Apesar do enfoque por vezes dado à cada elemento nas abordagens interseccionais, é no caráter relacional que a lógica teórica ganha corpo e demonstra desenvoltura capaz de ofertar um entendimento expressivo sobre as questões de representatividade, reconhecimento e legitimidade. A centralidade que o gênero ocupa no mundo do trabalho, sob uma perspectiva que se orienta pela tríade denominada interseccional, se efetiva a partir da interdependência com os outros elementos. Embora a hegemonia masculina se apresente como um fator de dominação, não é possível considerá-lo exclusivo. Significa dizer que, além da divisão sexual do trabalho, exposta nos âmbitos doméstico e profissional a partir dos princípios de separação e hierarquização (HIRATA; KERGOAT, 2007), outras formas de assimetrias podem se manifestar ao estabelecimento de um sistema que opera distintamente nas suas estruturações. Falamos, portanto, sobre como os mecanismos de opressão podem figurar distintamente entre as expressões das desigualdades ${ }^{6}$, mas sem haver uma sobreposição, pois, "retirar uma ou outra da análise significa perder parte significativa da

\footnotetext{
6 Biroli e Miguel (2015, p. 42), ao aferirem o aspecto da renda nas economias familiares brasileiras (dados do IPEA 2014), indicaram a existência de uma pirâmide onde os "patamares superiores de rendimento médio e ocupações mais valorizadas", eram ocupados por homens brancos no topo. Logo abaixo as mulheres brancas, seguidas por homens negros e, na base, mulheres negras.
} 
A reconfiguração do mundo do trabalho: o gênero como categoria essencial ao debate | João Matheus Soares Miranda

descrição da realidade" (BIROLI; MIGUEL, 2015, p. 41).

Buscamos demonstrar que, a partir do gênero e sua centralidade na lógica de operação do mercado de trabalho, especialmente no Brasil, é possivel esmiuçarmos outras variáveis que se enlaçam e imbricam por uma dinâmica de desigualdades e assimetrias. Embora não exista um consenso teórico e conceitual sobre a compreensão dos fenômenos que envolvem o gênero no mundo laboral, ou seja, matizes e correntes discutam vigorosamente sobre outros elementos estruturados pela hierarquização das opressões, abordagens que não trouxerem a dimensão das mulheres ao debate estarão fadadas ao afastamento da realidade e desconexão com as relações sociais contemporâneas.

\section{Considerações finais}

A repercussão do gênero no mundo do trabalho, a partir da sua centralidade e o inadiável enfrentamento das desigualdades constatadas, postas em pauta pelas distinções de assimetria e hierarquizações, figuram como um dos essenciais temas aos estudos das ciências sociais. Aos que se debruçam efetivamente nas relações sociais originadas pelas formas de organizações laborais da contemporaneidade, provocados ao estudo sistemático necessário à compreensão dos fenômenos de um mundo do trabalho reconfigurado, multifacetado e polissêmico, evidenciar o gênero como elemento da análise é fator imprescindível ao avanço sociológico, não exclusivamente pelo debate que se apresenta à vida das mulheres trabalhadoras, mas pela amplitude que se desenrola a partir do gênero.

Como buscamos demonstrar, seja por abordagens que privilegiam a questão da classe como ponto de partida ou até mesmo os desdobramentos da lógica interseccional, existe um sistema social de desigualdades em detrimento das mulheres, que se vincula à forma de operação e funcionamento do mercado. A divisão sexual do trabalho é o mecanismo que estabiliza a alimenta o sistema de hierarquização, tal qual se apresenta na realidade do mundo laboral. No entanto, se faz necessário salientar que existem movimentos sócio-políticos que se mobilizam em torno das pautas identificadas pelas mulheres e suas reivindicações. É nesse sentido que 
A reconfiguração do mundo do trabalho: o gênero como categoria essencial ao debate | João Matheus Soares Miranda

surge a alternativa de pensarmos a divisão sexual do trabalho a partir das cada vez mais expressivas lentes teórico-conceituais das mulheres, virtude que se constituiu justamente por uma especificidade, "é um movimento que produz sua própria reflexão crítica, sua própria teoria" (PINTO, 2010, p. 15).

Quando a centralidade do gênero ao mundo do trabalho é elencada como fenômeno essencial ao intento de suscitar um debate inadiável, significa dizer que estamos atentos às demandas e pautas que há décadas já são enfrentadas pelas mulheres, seja na produção acadêmica e intelectual ou na esfera do cotidiano frente às desigualdades históricas até hoje presentes nas trajetórias das trabalhadoras. Temas como a globalização, precarização precariedade dos trabalhos e contratos, regionalização, inserção e permanência em postos de trabalho e emprego, por exemplo, não conseguem ser compreendidos de forma robusta ao largo do entendimento da reconfiguração do mundo do trabalho e a temática de gênero, no mínimo, deve tangenciar o debate. Essa necessidade não apenas fundamenta e justifica a produção do presente artigo, mas sustenta a ideia de que as relações de trabalho no século XXI estão determinadas pela participação feminina no mercado de trabalho. Fato que, não apenas enseja a atenção relativa às pautas que surgem diante das novas características do capitalismo dos nossos tempos, como também arrazoa e dimensiona a fundamental contribuição teórica sobre o gênero (e suas implicações sóciohistóricas) no mundo do trabalho.

\section{Referências:}

ALVES, Giovanni. Trabalho e subjetividade: o metabolismo social da reestruturação produtiva do capital. Tese de Livre-docência. Unesp: Marília, 2008.

ANTUNES, Ricardo. Adeus ao trabalho?: ensaio sobre as metamorfoses e a centralidade no mundo do trabalho. 16 a edição. São Paulo: Cortez, 2015.

BIROLI, F; MIGUEL, L.F. Gênero, raça e classe: opressões cruzadas e 
A reconfiguração do mundo do trabalho: o gênero como categoria essencial ao debate | João Matheus Soares Miranda

convergência na reprodução das desigualdades. Mediações, Londrina, v.20, n.2, pp. $27-55,2015$.

BRUSCHINI, C. O Trabalho da Mulher Brasileira nas décadas recentes. Revista Estudos Feministas, vol.2, $\mathrm{n}^{\circ} 3$ out/1994. IFCS/UFRJPPCIS/UERJ. Rio de Janeiro.1994

BRUSCHINI, Cristina. Trabalho e gênero no Brasil nos últimos dez anos. Cadernos de Pesquisa, v. 37, n. 132, 2007.

CASTELlS, Manuel. A rede e o Ser. A revolução da Tecnologia da Informação in: A Sociedade em rede. São Paulo: Editora Paz e Terra.1999

DRUCK, Graça. Flexibilização e precarização: formas contemporâneas de dominação do trabalho. Caderno CRH, Salvador, n. 37, p. 11-22, jul./dez, 2002 .

BOLTANSKI, Luc. CHIAPELLO, Éve. O novo espirito do capitalismo. Ed. Martins Fontes. São Paulo: 2009.

GUIMARÃES, Nadya Araújo. Caminhos cruzados: estratégias de empresas e trajetórias de trabalhadores - São Paulo: USP, curso de pós-graduação em Sociologia, Ed. 34, 2004.

GUIMARÃES, Nadya Araújo. Trabalho flexivel, empregos precários? Uma comparação Brasil, França, Japão/Nadya Araújo Guimarães, Helena Hirata e Kurumi Sugita, organizadoras - São Paulo: Editora da Universidade de São Paulo, 2009.

HIRATA, Helena. Globalização, trabalho e gênero. Revista de Politicas Públicas, v. 9, n. 1, p.111-128, jul./dez. 2005

HIRATA, Helena; KERGOAT, Danièle. Novas configurações da divisão sexual do trabalho. In: Cadernos de Pesquisa, v. 37, n. 132, p. 595-609, set./dez. 2007.

HIRATA, Helena. A Precarização e a Divisão Internacional e Sexual do Trabalho. Sociologias, Porto Alegre, ano 11, no 21, jan./jun. 2009, p. 24-41.

HIRATA, Helena. Gênero, classe e raça Interseccionalidade e consubstancialidade das relações sociais. Tempo social. vol. $26 \mathrm{n}^{\circ} .1$ São Paulo Jan./Jun 2014

HIRATA, Helena. Mudanças e permanências nas desigualdades de gênero: divisão sexual do trabalho numa perspectiva comparada. Friedrich Ebert Stiftung Brasil, n.7, 2015

HIRATA, Helena. Gênero, patriarcado, trabalho e classe. Revista Trabalho Necessário, Rio de Janeiro, ano 16, no 29.2018, p. 14 - 27. 
A reconfiguração do mundo do trabalho: o gênero como categoria essencial ao debate | João Matheus Soares Miranda

KERGOAT, Danièle. Ouvriers=ouvrières. In: Critique de l'Economie Politique, $\mathrm{n}^{\circ}$ 5. Paris, 1978.

PINTO, Céli Regina Jardim. Feminismo, História e Poder. Rev. Sociol. Polít., Curitiba, v. 18, n. 36, jun. 2010, p. 15-23.

PINTO, Céli Regina Jardim. É possível falar de um discurso feminista no século XXI?. In: MENDONÇA, Daniel de; RODRIGUES, Léo P.; LINHARES, Bianca (orgs.). Ernesto Laclau e seu legado transdisciplinar. Editora Intermeios, São Paulo, 2017.

PISCITELLI, Adriana. Interseccionalidade, categorias de articulação e experiências de migrantes brasileiras. Sociedade e Cultura, v.11, n.2, jul/dez, 2008, p. 263-274.

ROSENFIELD, Cinara. Autoempreendedorismo: forma emergente de inserção social pelo trabalho. Revista Brasileira de Ciências Sociais, Vol 30 (89), 2015, p. 115-197. 